International Journal on Information Sciences and Computing, Vol. 6 No. 1 January 2012

\title{
AN INTELLIGENT WAY FOR POWER OPTIMIZATION IN WIRELESS SENSOR NETWORK
}

\author{
Karthik D. ${ }^{1}$, Dr Nagarajan $\mathbf{S}^{2}$ \\ ${ }^{1}$ Research scholar, Information Technology, Hindustan University, Padur, Chennai \\ ${ }^{2}$ Professor and Head, Information Technology, Hindustan University, Padur, Chennai \\ Email: ${ }^{1}$ karthick_softwarepro@yahoo.co.ina, ${ }^{2}$ snagarajan1960@gmail.com
}

\section{ABSTRACT}

Wireless sensor networks (WSNs) are composed of numerous autonomous sensor nodes. WSNs sensor node detects the corresponding event and sends it to the sink via intermediaries. Each node in WSNs are driven by limited power supply .hence power possess by each node in WSNs should be optimized. In this paper we propose dynamic routing based power optimization method (DRBPO) which route the packet based on energy posses by each node and reduce traffic posses by each node. In case of ideal state nodes are driven by limited power. Hence all the nodes in WSNs can be efficiently utilized efficiently which extends the life of each node in WSN to its maximum. In Addition we propose the relationship between routing, traffic and power optimization.

Keywords wireless sensor network (WSNs), Dynamic Routing Based Power Optimization Method (DRBPO), autonomous mobile nodes, intermediaries, sink.

\section{INTRODUCTION}

A typical Wireless sensor network (WSNs) consists of numerous autonomous nodes. Which sense the data and send it to sink (base station) via intermediates nodes. WSNs are deployed in a harsh environment where charging or replacing the battery are not feasible. The facilities of sensors deployment and the cost reductions have increased use of wireless sensor networks. Today we find this kind of network in industrial monitoring, environmental data record [1] [2], home automation [3], fire detection [4], and medical [5] or even in military applications. A typical wireless sensor node consists of sensor/actuator, processor, memory, transceiver, power unit and mobilizes [6], [7], [8], [9].the fig 1 describe a typical Wireless sensor which consist of a sensors / actuators are used to sense the required information, the energy required to sense the data is considerably less. The energy required by a microcontroller to process the data is also fairly less. The (transceiver) Energy required for transmitting the data and energy required to receive data is considerably very high [10]. Which drastically decrease the energy level of the power unit.

This paper provides a practical model for energy efficient routing (DRBPO) this method proposed dynamic routing based power optimization .In traditional routing method will be done by finding the shortest path between source and base station. The data will be routed using the shortest path. There is no constrain

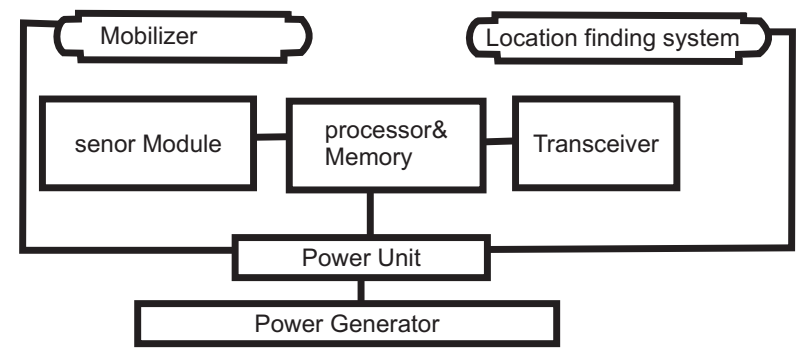

Fig. 1. A typical wireless sensor node

called energy because they are renewable resources. In WNSs the same traditional method cannot be applied because the nodes have limited energy. if any static routing path is used to forward the packet which drains the energy of sensor node near by the sink or the node frequently used by the shortest path, which leads to the physically prone of the particular node.

\section{DYNAMIC ROUTING BASED POWER OPTIMIZATION}

We proposed an optimal solution for power optimization in WSNs by efficiently utilizing all sensor nodes, which extends the life time of the entire WSNs. The dynamic routing based power optimization (DRBPO) provides a practical model for routing based on energy level of each sensor node. This Method dynamically constructs a routing table based on the 
energy level of each sensor in WSNs and energy required to transmit the data. The energy required to transmit and receive the sensed data is fairly high. This (DRBPO) method comprise of two build blocks namely.

The Energy Method: This method find the energy level of each sensor node, this information will be dynamically updated to its neighbouring nodes. If energy level of a sensor node decreases considerably it means that the driving force voltage decreases, hence each sensor node want to spend more energy for transmission.

Energy based routing: The DRBPO method route the packet by selecting the path dynamically based on the energy posses by each sensor node intimated by the energy method. This method dynamically constructs a routing table which calculate energy required for transmitting the given data and energy of each sensor node along the path. Based on these information's a suitable path will chosen for routing the packet .This optimization method decreases the energy consumption of each sensor node which extends the life time of the entire WSNs.

\section{DYNAMIC ROUTING TABLE FOR STATIC SENSORS}

Assume that a typical wireless sensor network as shown in Fig 1 which consists of six nodes. Initially all the node have maximum energy $100 \%$ at the time of deployment. Assume that for transmitting and receiving a bit of data requires $2 \%$ of the battery, to process a bit of data we require $1 \%$ of the battery. Each node can transmit a maximum of a bit at a give instance of time. Consider that a node A want to sent 5 bits of data to the sink node $F$.

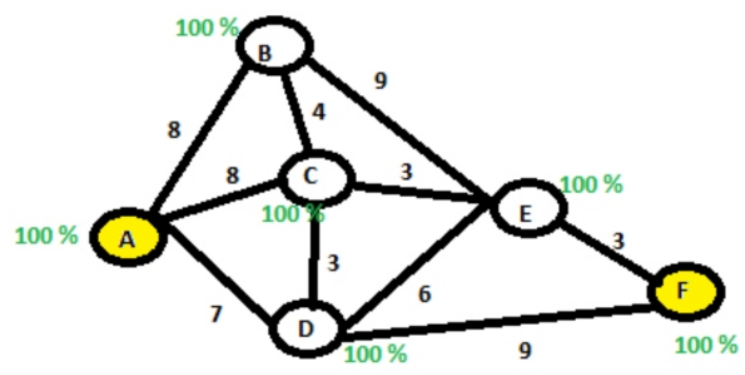

Fig. 2. A typical WSNs with Six nodes and their energy level

In traditional method a routing table will be built based on the cost between the nodes and intermediaries. The lowest cost path will be chosen for routing data as shown in routing table 1 . This traditional method is not convenient for WSNs which are driven by limited power supply. In the traditional method the routing path $A, C, E$ and $F$ will be chosen which contain less cost for transmission. This kind of routing mechanism is not an optimal routing mechanism for WSNs because they driven by limited power supply.

Table 1. Traditional Shortest Path

Routing Method

\begin{tabular}{|c|c|c|c|c|}
\hline Source & \multicolumn{2}{|c|}{ Intermediaries } & Sink & Cost \\
\hline A & B & E & F & 20 \\
\hline A & C & E & F & 14 \\
\hline A & D & E & F & 16 \\
\hline
\end{tabular}

We propose a Dynamic Routing Based Power Optimization mechanism (DRBPO) which dynamically crate and update the routing table parameter such as energy required for transmission and cost between the intermediate nodes. The energy posed by each nodes will be found using Energy method. Calculate the percentage of energy required to transmit the sensed data from source and sink, calculate the number of hop count required to forward the data and calculate the cost required to forward the data along the path. Select the routing path based on the energy level of each sensor node along the path, hop count and cost as shown table 2.

Table 2. Dynamic Routing Table with Energy Level, Hop Count and Cost

\begin{tabular}{|c|c|c|c|c|c|c|}
\hline Source & \multicolumn{2}{|c|}{ Intermediarie S } & SINK & HOP & Energy Req & Cost \\
\hline A & B & E & F & 2 & 14 & 20 \\
\hline A & C & E & F & 2 & 14 & 14 \\
\hline A & D & E & F & 2 & 14 & 16 \\
\hline A & D & & F & 1 & 9 & 16 \\
\hline
\end{tabular}

In the above dynamic routing table the path $A$, $C, E, F$ will be the optimal path in case of cost, but the energy required is $14 \%$. The path $A, D, F$ is next cost-effective path it requires only $9 \%$ of the battery. The difference between cost as compared to the path $A, C, E, F$ and $A, D, F$ is 2 which is negotiable .The fig 2 explain the transmission of data and their corresponding energy level of each node along the path. 


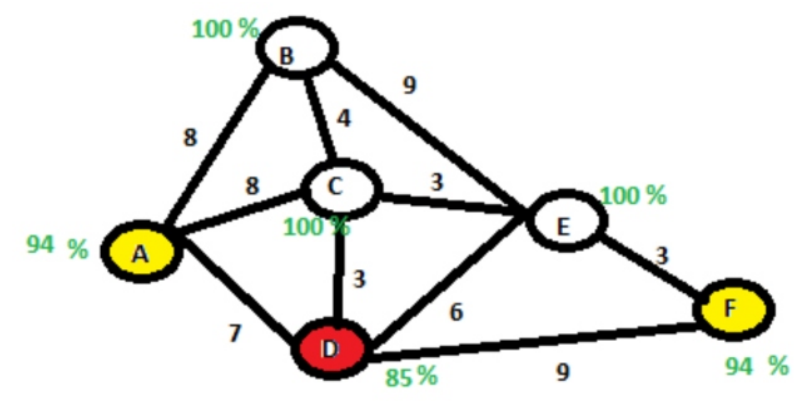

Fig. 3. Explain Energy level for each sensor node after completing three transmissions

Hence the path $A, D, F$ will be chosen for transmitting first three bits of the given data. After three transmissions the power posed by each node along the path is depicted in table 3

Table 3. Energy Level of the Node A, D, and F

\begin{tabular}{|c|c|}
\hline NODE & ENERGY LEVEL \\
\hline$A$ & 94 \\
\hline$D$ & 85 \\
\hline$F$ & 94 \\
\hline
\end{tabular}

Table 3 indicate that node D (85\%) energy level is drastically decreasing as compared to A (94\%) and $F(94 \%)$. if we use the same path with lead to physical prone of the node $D$, hence a new dynamic path will chosen for remaining transmission using dynamic routing table with updated information as show in table 4

\section{Table 4. Explain Energy Level of Each Sensor Node and Cost Required}

\begin{tabular}{|c|c|c|c|c|c|c|}
\hline $\begin{array}{c}\text { Source } \\
\text { / Power }\end{array}$ & $\begin{array}{c}\text { Intermediaries/ } \\
\text { Power }\end{array}$ & Sink & HOP & $\begin{array}{c}\text { Energy } \\
\text { Req }\end{array}$ & Cost \\
\hline $\mathrm{A} / 94$ & $\mathrm{~B} / 100$ & $\mathrm{E} / 100$ & $\mathrm{~F} / 94$ & 2 & 14 & 20 \\
\hline $\mathrm{A} / 94$ & $\mathrm{C} / 100$ & $\mathrm{E} / 100$ & $\mathrm{~F} / 94$ & 2 & 14 & 14 \\
\hline $\mathrm{A} / 94$ & $\mathrm{D} 1 / 85$ & $\mathrm{E} / 100$ & $\mathrm{~F} / 94$ & 2 & 14 & 16 \\
\hline $\mathrm{A} / 94$ & $\mathrm{D} / 85$ & - & $\mathrm{F} / 94$ & 1 & 9 & 16 \\
\hline
\end{tabular}

The path $A, C, E$, and $F$ can be used to send the next two bits of data because is required $14 \%$ of energy which is similar to all other energy requirement, if we compare with the cost require to transmit the data, the chosen path is comparatively less as compared to other path cost. After transmitting all the five bits using the path $A, D, F$ and the path $A, C, E$ and $F$ the energy level of each sensor node participated in the transmission are depicted in the table 5 .

Table 4. Energy Level of each Participant after Transmission

\begin{tabular}{|c|c|}
\hline NODE & ENERGY LEVEL \\
\hline$A$ & 90 \\
\hline C & 90 \\
\hline$D$ & 90 \\
\hline$E$ & 90 \\
\hline$F$ & 90 \\
\hline
\end{tabular}

Table explain that all the node in a given WSNs can be efficiently utilized which extends the life time of the battery and also reducenetwork traffic by choosing different path dynamically. If a graph is drawn between exiting and proposed method, the graph indicate that the proposed method optimize all the sensors in given WSNs by consuming the power

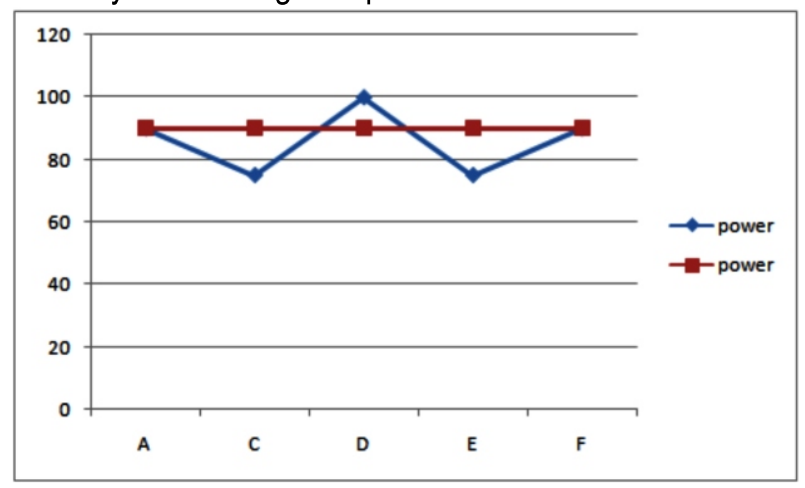

Fig. 4. Indicate a graph between the existing and poposed methos

The graph determine that the popes system optimize the sensor nodes energy level along the routing path which prolong the life time of each sensor node in WSNs.

Ideal state: All sensor nodes will be in an ideal state when nodes are not doing any task. Ideal state determines that all nodes in this state will be driven by minimal energy which all so reduce the energy consumption of each nodes considerably.

\section{DRBPO ALGORITHM}

We propose a new algorithm for dynamic routing based power optimization method which forward the given packets based on the energy level of each sensor node along the path. This method calculates 
the energy required for transmission, no of Hop count and cost. Based on calculated parameters a optimal path will be chosen and the chosen path may change dynamically based on the energy level on sensors along the path.

\section{ALGORITHM}

Step 1: Find the initial energy level of each sensor node using energy method and update this information to its corresponding neighbours periodically.

Step 2: The node on receiving this information dynamically constructs a dynamic routing table which contain energy level, Hop count and cost.

Step 3: Calculate the amount of energy required for transmitting a bit of data, calculate no of hop count the transmission requires and calculate the associated cost long the path.

Step 4: Select the routing path to forward the given data based on parameters energy required, Hop count and Cost, Route the packet along the path.

Step 5: Repeat step 1, step 2 and step 3 periodically.

Step 6: Select path based on energy, hop and cost, forward the data along the path which optimize the usage of the battery which extends the life time of WNSs.

\section{RELATIONSHIP BETWEEN ROUTING, TRAFFIC AND ENERGY LEVEL IN WSNS}

The parameters routing $(\mathrm{x})$, traffic $(\mathrm{y})$ and energy (z) are interrelated with each other. The fig 3 indicates that by performing optimal routing which considerably reduces the energy and traffic. Hence we can derive the relationship between these parameters as $x$ is directly propositional to $z$ and $y, z$ is directly proportional to $\mathrm{y}$ and $\mathrm{x}$

\section{$X \alpha Y \alpha Z$}

\section{CONCLUSION}

In this paper we propose dynamic routing based on power optimization method. This method optimize the energy level of each sensor in wireless sensor network, which extends the life time of each sensor node by selecting an optimal path in dynamic routing table which contain the percentage of energy required for transmitting a bit of data, no of hop count required for transmission and cost associated with the path. This method extensively increases the life time of each sensor node by balancing the transmission which increases the life time of entire WSNs.

\section{REFERENCES}

[1] Kim S, Pakzad S, Culler DE, Demmel J, Fenves G, Glaser S, Turon M. Wireless sensor networks for structural healthmonitoring. SenSys, Campbell AT, Bonnet P, Heidemann JS (eds.), ACM, 2006; 427-428.

[2] Welsh M. Deploying a sensor network on an active volcano. USENIX Annual Technical Conference, General Track,USENIX, 2006.

[3] Baker CR, Armijo K, Belka S, Benhabib M, Bhargava V,Burkhart N, Minassians AD, Dervisoglu G, Gutnik L, HaickMB, et al.. Wireless sensor networks for home health care. AINA Workshops (2), IEEE Computer Society, 2007; 832-837.

[4] Thierry AS, Francois SJ, de Gentili Emmanuelle, Bernadette C.Using wireless sensor network for wildfire detection. a discrete event approach of environmental monitoring tool. Environment Identities and Mediterranean Area, 2006. ISEIMA '06. Firstinternational Symposium on, 2006.

[5] Malan D, Fulford-Jones T, Welsh M, Moulton S. Codeblue: An ad hoc sensor network infrastructure for emergency medical care. International Workshop on Wearable and Implantable Body Sensor Networks, 2004.

[6] K. Römer and F. Mattern," The design space of wireless sensor networks", Wireless Communications, IEEE, Volume 11, Issue 6, Dec.2004 Page(s):54 - 61.

[7] M. A. M. Vieira, C. N. Jr. Coelho, D. C. Jr. da Silva, and J. M. da Mata, "Survey on wireless sensor network devices", Emerging Technologies and Factory Automation, 2003. Proceedings. ETFA '03. IEEE Conference. Volume 1, 16-19 Sept. 2003 Page(s):537 - 544 vol.1.

[8] J. Feng, F. Koushanfar, and M. Potkonjak, "System-architectures for sensor networks issues, alternatives, and directions", Computer Design: VLSI in Computers and Processors, 2002. Proceedings. 2002 IEEE International Conference on 16 -18 Sept. 2002 Page(s):226 - 231

[9] Optimization of Power Consumption in Wireless Sensor Networks, urendra bilouhan, Prof.Roopam Gupta, International Journal of Scientific \& Engineering Research Volume 2, Issue 5, May-2011 1 ISSN 2229-5518 2]

[10] Maximum Lifetime Routing in WirelessSensor Networks Jae-Hwan hang, Member, IEEE, and Leandros Tassiulas, Member, IEEE, IEEE/ACM RANSACTIONS ON NETWORKING, VOL. 12, NO. 4, AUGUST 2004[1]. 